Research article

\title{
Power, perspective, and privilege: The challenge of translating stakeholder theory from business management to environmental and natural resource management
}

\author{
R.M. Colvin ${ }^{\mathrm{a}, *}$, G. Bradd Witt ${ }^{\mathrm{b}}$, Justine Lacey ${ }^{\mathrm{c}}$ \\ ${ }^{a}$ Crawford School of Public Policy, Australian National University, J.G. Crawford Building \#132, Acton, ACT, 2602, Australia \\ ${ }^{\mathrm{b}}$ School of Earth and Environmental Sciences, The University of Queensland, Chamberlain Building \#35, St Lucia, QLD, 4072, Australia \\ ${ }^{\mathrm{c}}$ Responsible Innovation Future Science Platform, Commonwealth Scientific and Industry Research Organisation (CSIRO), Dutton Park, QLD, 4102, Australia
}

\section{A R T I C L E I N F O}

\section{Keywords:}

Engagement

Landscape preferences

Values

Decision-making

\begin{abstract}
A B S T R A C T
Stakeholder analysis and engagement is a central tenet for understanding and solving sustainability challenges, and is applied widely in environmental and natural resource management (ENRM). The practice in ENRM follows translation of stakeholder theory from its origins in business management to the sustainability sector. In this analytical essay we explore key concepts in ENRM research and practice to examine complexities that have accompanied this translation to ENRM. In particular, we consider the centrality of stakeholders' landscape perspectives in defining their stake in ENRM issues, and through this lens examine the limitations that are inherent in the classic 'hub-and-spoke' model of stakeholder analysis that is the theoretical underpinning for ENRM stakeholder analysis and engagement practice. We argue that unlike the traditional business context where both power and perspective are centred on the business entity that then defines other stakeholders in reference to itself, in ENRM, stakeholder relations are centred on an ENRM issue, typically a landscape or the implications of policy change on a landscape. As a consequence, decision-making power is decentred onto one of several stakeholders; often a government or other high power entity, implicitly conferring privilege to those powerful stakeholders' landscape perspectives over those held by low power stakeholders. We conclude with priorities for foregrounding power and explicating landscape perspectives to identify privilege in ENRM. We direct these insights especially to those ENRM actors who have the dual roles of adjudicator and privileged stakeholder such that they do not inadvertently perpetuate power imbalances through the privilege of aligning their decision-making power with their landscape perspectives.
\end{abstract}

\section{Introduction}

Analysis of, and engagement with, stakeholders is a critical element of environmental and natural resource management (ENRM). In ENRM, talk of stakeholders can mean communities, interest groups, advocacy groups, discourse coalitions, organisations, social constituencies (sections of society with a shared characteristic but without formal membership, e.g. women) and/or individual people (Billgren and Holmén, 2008; Reed, 2008; Rastogi et al., 2010; Colvin et al., 2016a). This stems from the pivotal and highly influential work of Freeman (1984, p. 46), which is most commonly cited for the fundamental definition of stakeholder as "any group or individual who can affect or is affected by the achievement of an organisation's objectives". The subject of this quote - an organisation - reflects the disciplinary grounding for Freeman's (1984) work in the business management discipline. Here, we argue that while the translation of stakeholder theory from business management to ENRM was a necessary and valuable advancement for the democratisation of ENRM decision-making, a fundamental contextual difference between the two applications raises challenges for ENRM that must be recognised and navigated.

In this article, we discuss the origins of stakeholder theory in business management and explore its translation to, and ongoing development within, the ENRM context. We then examine complexities with classifying stakeholders in ENRM, and the multi-faceted relationship between stakeholders and the landscape in the ENRM context. In so doing, we grapple with the relationship between two critical concepts:

\footnotetext{
* Corresponding author.

E-mail addresses: Rebecca.Colvin@anu.edu.au (R.M. Colvin), bwitt@uq.edu.au (G.B. Witt), Justine.Lacey@csiro.au (J. Lacey).
} 
landscape perspective, the way an actor defines the composition, symbolic meaning and appropriate use of the landscape, informed by their values and experiences (Meinig, 1979); and power, the ability of a social actor to realise their aims despite resistance (Weber, 1978). The interaction of perspective and power in the ENRM context, we will argue, privileges some landscape perspectives over others. These privileged landscape perspectives become viewed as the norm against which alternative landscape perspectives, especially those held by low power stakeholders, must compete. We conclude by highlighting some ways forward for ENRM stakeholder analysis and engagement scholarship and practice.

\section{The origins of stakeholder theory}

Freeman's (1984) stakeholder theory proposed a paradigm shift from business responsibility to shareholders (those with a financial interest in the performance of the firm), to responsibility to all stakeholders. This was to adapt the sphere of accountability of business from those who are directly benefitting from the business' actions, to all of those who can affect, or are affected by the business' actions (Billgren and Holmén, 2008; Laplume et al., 2008; Miles, 2012). Stakeholder theory was perceived of as both a strategic and normative imperative; stakeholders could be included in business decision-making either to strategically improve long-term outcomes for the business, or because it was normatively seen as the socially responsible thing to do (Freeman, 1984; Laplume et al., 2008; Reed, 2008).

Due to the conceptualisation in business management, the process of identifying who are the relevant stakeholders has focused on the relationship of individuals and groups in relation to the firm (the business entity), leading to categorisations along the lines of "customers, suppliers, employees, shareholders, and community" (McVea and Freeman, 2005, p. 62), or to expand; "shareholders and investors, employees, customers, and suppliers, together with what is defined as the public stakeholder group: the government and communities that provide infrastructures and markets whose laws and regulations must be obeyed and to whom taxes and other obligations may be due" (Clarkson, 1995, p.106). This represents a type of perspective where the impact of decisions can be traced through measurable links (generally describing economic exchange or regulatory control) between the firm's actions and its stakeholders (Mitchell et al., 1997).

As described by McVea and Freeman (2005, p. 60), "stakeholders are treated not as morally important individuals, but as abstractions, characterized by the roles that they play". This in effect organises the social system as a series of social categories defined by the firm's relationship with society, i.e. it is firm-centric. Crane and Ruebottom (2011, p. 77) argue that the firm-centric structure of stakeholder theory runs "the risk that "stakeholder" will become a meaningless term" as the categories by which stakeholders are organized are superficial outside of the context of the firm. This accords with work by Rowley and Moldoveanu (2003), which proposed that stakeholders should be conceptually organized by pre-existing social groupings, as opposed to their functions in relation to the firm. Reflecting these limitations and others, Miles (2012, 2015) describes the term stakeholder as an "essentially contested concept" where there are multiple ways the term is interpreted and, therefore, how stakeholders are identified. Despite these cautions, and through evolving theory and practice (sometimes incorporating these critiques), stakeholder analysis remains prominent in business management, and has since become a key element of ENRM.

\section{Stakeholder analysis and engagement in ENRM}

With the growing impetus for public participation in ENRM (Mohai, 1987; Sample, 1993; Miller, 1999; Lockwood et al., 2010; Buijs and Lawrence, 2013; Guerrero et al., 2013), stakeholder theory was adapted from business management for application in ENRM (Grimble and Wellard, 1997; Billgren and Holmén, 2008; Reed, 2008). This paralleled the 'participatory turn' in ENRM (Ross et al., 2016), wherein greater attentiveness was given to the role of the public in decision-making, justified by the belief that integration of a range of voices in decisions improves outcomes for people and the environment.

In the new participatory ENRM decision-making arena, stakeholder theory retained the focus from business management on measurable links for stakeholder identification. Within the broad scope of public participation in ENRM, stakeholder theory is operationalised as stakeholder analysis and engagement, where analysis is the process of understanding stakeholders to inform decision-making, and engagement the process of involving stakeholders in decision-making (Reed, 2008). Stakeholder analysis is described as a process that (Reed et al., 2009, p. 1393):

i) defines aspects of a social and natural phenomenon affected by a decision or action;

ii) identifies individuals, groups and organisations who are affected by or can affect those parts of the phenomenon (this may include nonhuman and non-living entities and future generations); and

iii) prioritises these individuals and groups for involvement in the decision-making process.

Stakeholder analysis may be conducted solely for the purposes of understanding the social dimension of an ENRM issue. However, stakeholder analysis is usually followed by some form of stakeholder engagement. This may occur specifically with communities or interest groups, or both. Stakeholder engagement is an ongoing process of knowledge exchange between decision-makers and stakeholders about a given project or issue (Reed et al., 2009; Cundy et al., 2013). Throughout this process, stakeholders participate in a range of activities that aim to elicit their views and encourage dialogue between stakeholders and decision-makers about the project or issue. Activities include participation in committees, responding to surveys and polls, attending discussion forums, writing submissions, and receiving information (Rowe and Frewer, 2000; Reed, 2008; Colvin et al., 2016b). Based on process design, stakeholders may be 'empowered' where they have control, to some extent, over the decisions being made (e.g., IAP2, 2015). In other cases, stakeholder engagement may be tokenistic, where stakeholders' perspectives either are not sought, or are sought but not incorporated into the decision-making process in a meaningful way (Arnstein, 1969; Hindmarsh and Matthews, 2008; Reed et al., 2009; Ulibarri et al., 2019). This highlights that stakeholder engagement can range on a spectrum depending on the nature of the issue, timeframes and resources available, and the power relations between stakeholders and key decision-makers.

While stakeholder analysis and engagement and public participation are often used interchangeably, Reed (2008) draws a key distinction between stakeholder analysis and engagement specifically and public participation more broadly. Stakeholder analysis and engagement targets analysis and/or engagement of individuals and groups based on direct relationship to the ENRM issue, while public participation includes all individuals and groups in society regardless of whether they have a direct relationship to the ENRM issue. This is based on Freeman's (1984) definition that stakeholders are considered those who are affected by, or can affect a decision.

\section{The practice of ENRM stakeholder analysis and engagement}

For ENRM stakeholder analysis and engagement, a necessary early step is stakeholder identification (Mitchell et al., 1997; Bryson, 2004; Prell et al., 2007; Billgren and Holmén, 2008; Reed et al., 2009, 2013; Miles, 2015; Colvin et al., 2016a). Prell et al. (2009, p. 515), building on Freeman's (1984) initial conceptualisation, describe ENRM stakeholders as "individuals who affect or are affected by certain decisions and actions ... clustered into stakeholder categories according to their similarity in views, position(s) on an issue, and/or how they affect or are 
affected by the issue". In practice, this leads to ENRM stakeholder identification including interested parties such as local communities and interest groups, distinct from the rest of the public, i.e. the 'citizenry' (Fig. 1a) (Kahane et al., 2013; Aanesen et al., 2014; Fischer et al., 2014; North et al., 2014; Soma and Vatn, 2014; Uribe et al., 2014). The distinction between stakeholders and the citizenry is based on the argument that stakeholders represent specific interests, while the citizenry serves to represent the 'public good' (Carson, 2009; Soma and Vatn, 2014; Colvin et al., 2016a), and community is a special type of stakeholder with important local interests (Lacey and Lamont, 2014). However, these categorisations align closer to a theoretical ideal than a true reflection of social reality which is necessarily more complex and contestable (Fig. 1b).

In ENRM, the process of stakeholder identification can be especially challenging as the interconnectedness of natural systems can lead to who is considered a stakeholder including "almost everyone and everything" (Billgren and Holmén, 2008, p. 553). For instance, some have proposed the environment itself ought to be considered a stakeholder in such issues (Starik, 1995), however this tends to be a minority view, with the prevailing approach framing the environment instrumentally in terms of human interests (Phillips and Reichart, 2000). The potential for identification of ENRM stakeholders to include all people creates challenges for ENRM (Reed et al., 2009). While public participation broadly includes all individuals and groups in society, following Freeman (1984) ENRM stakeholder analysis and engagement includes only those who are affected by or can affect an ENRM issue (Reed et al., 2009). The ability to affect or be affected by (Fischer et al., 2014) an ENRM issue also describes those who may have an interest in (Soma and Vatn, 2014) an ENRM issue. This criterion for the identification of stakeholders indicates an instrumental or economic view of 'affect', indicating that solely moral impacts - unless the moral impacts are coupled with the power to be able to affect the issue (Grimble and

(a)

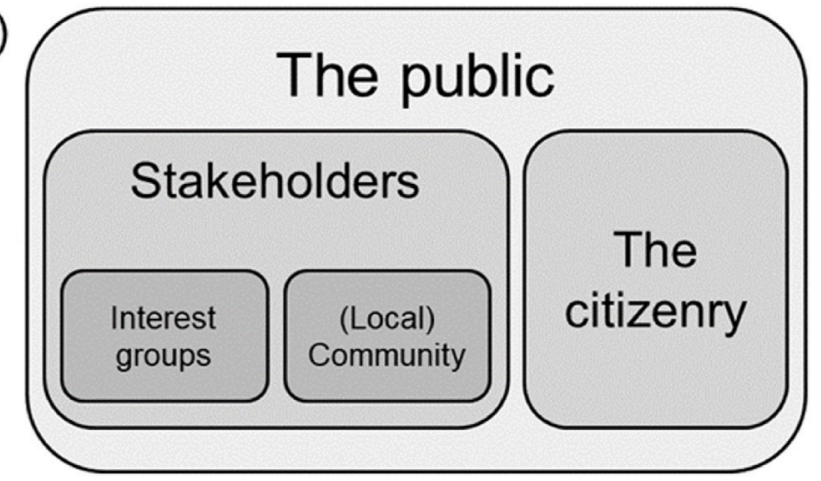

(b)

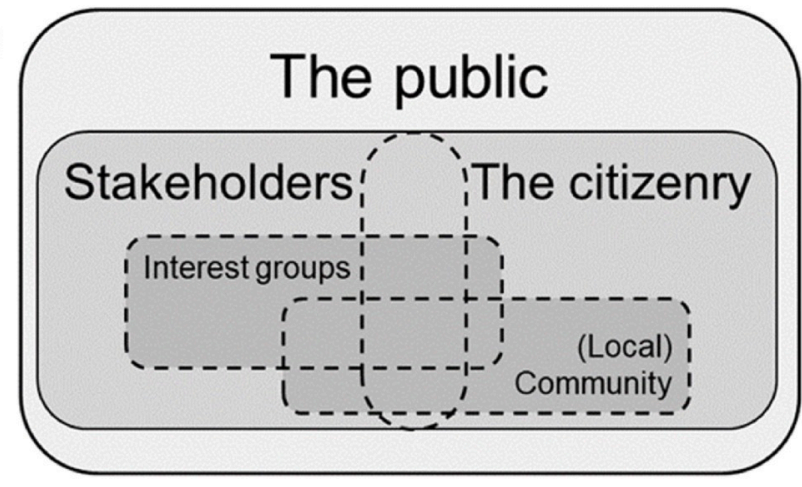

Fig. 1. The hierarchical arrangement of key groups in ENRM stakeholder identification. Diagram (a) is an idealised representation of the constitution of 'the public', from the perspective of ENRM stakeholder analysis and engagement. Diagram (b) shows a messy representation of the same categories as they may be experienced in real-world ENRM issues.
Wellard, 1997; Prell et al., 2009) - do not warrant inclusion as a stakeholder, as these concerns are not within the scope of what is considered 'affected'.

\section{Categorising stakeholders and the 'usual suspects' in ENRM}

Reed and colleagues (Reed, 2008; Reed et al., 2009) have argued that in ENRM, stakeholders tend to be self-evident, meaning that stakeholders are drawn from, and reflect, pre-existing social structures (e.g. communities, interest groups, advocacy coalitions, organisations, social constituencies or individual people). This leads to a range of types of stakeholders identified for any given ENRM issue. Kahane et al. (2013) outlined several attributes across which stakeholders can differ (Table 1); indicating that in addition to differences in the social structures from which stakeholders are drawn, participation in ENRM decision making can be a central or peripheral element of the stakeholders' objectives (Rowley and Moldoveanu, 2003).

While stakeholders can be drawn from a range of pre-existing social structures and their group attributes vary, there is evidence of repeat identification and inclusion of the 'usual suspects' in ENRM (Reed et al., 2009; Colvin et al., 2016a), described by Kivits (2011, p. 320) as "communities, NGOs, government and the private sector". Repeat inclusion of these 'usual suspects' amplifies existing power dynamics through the institutionalisation of stakeholder norms and relations. These stakeholder categorisations are present in ENRM as: industry (the private sector, e.g. mining, energy, agriculture, forestry, aquaculture and fisheries, depending on the issue); jurisdictional governments; environmentalists or conservationists (NGOs) and; community (Carr and Tait, 1991; Beedell and Rehman, 2000; Kächele and Dabbert, 2002; Lewicki et al., 2003; Moore and Koontz, 2003; Wilson, 2004; Winter and Lockwood, 2004; Walker, 2006; Yasmi et al., 2006; Brummans et al., 2008; Bryan, 2008; Kash, 2008; Witt et al., 2009; Rastogi et al., 2010; Treffny and Beilin, 2011; Fox et al., 2013; Kindermann and Gormally, 2013; Redpath et al., 2013; Silverstri et al., 2013). As a result of the 'usual suspects' in ENRM stakeholder engagement being drawn from pre-existing social constituencies, organisations, and institutions, when stakeholders are categorised for engagement in an ENRM issue, the power, privileges, and vulnerabilities inherent in broader society are

Table 1

Key attributes across which stakeholders can differ (Kahane et al., 2013).

\begin{tabular}{ll}
\hline Group attribute & Description \\
\hline Organisational & $\begin{array}{l}\text { Can exhibit varying degrees of structure, ranging from } \\
\text { highly formal (organized around charters, decision } \\
\text { procedures, membership rules, enduring and well-defined } \\
\text { interests or identities) to informal (organized around } \\
\text { loosely-defined or dynamic identities or interests and } \\
\text { transient membership). } \\
\text { Can be non-profit, volunteer and grassroots, all the way } \\
\text { through to professional with paid staff and private funding. } \\
\text { Can be more or less oriented toward political action, } \\
\text { lobbying, campaigning, public education, or member } \\
\text { services provision. } \\
\text { Missions } \\
\text { Can be more or less woven into power structures and } \\
\text { governance networks. } \\
\text { Can be local, regional, national or international. } \\
\text { Canstitutionalisation claim to represent their members alone, or to represent } \\
\text { others sharing interests/identities with their members, or to } \\
\text { represent the interests of populations not well represented } \\
\text { in the group itself (as with 'astroturf' organisations, which } \\
\text { profess to represent a grassroots movement while in fact } \\
\text { being centrally orchestrated). } \\
\text { Can be the sole or authorized representative for a category } \\
\text { of stakeholders, or can exist on a contested or crowded field } \\
\text { of potential representatives. } \\
\text { Can claim different kinds of epistemic authority-for } \\
\text { example, to speak from the perspective of a particular social } \\
\text { group, or to speak from expert experience and training that } \\
\text { the rest of the public typically lacks. }\end{array}$ \\
\hline
\end{tabular}


carried over into, and can influence, stakeholder analysis and engagement (Billgren and Holmén, 2008; Van Assche et al., 2017). Repeat identification of the 'usual suspects' via informal or formal stakeholder identification and analysis processes can intentionally or unintentionally entrench existing social roles and power dynamics even further through the process of stakeholder engagement (Colvin et al., 2016a, 2019).

For example: local communities are most likely to experience direct impacts of a land use change (Parsons et al., 2014); industry has access to the financial resources to shape land use change (Measham and Fleming, 2013); government has overriding policy and decision making discretion (Zammit et al., 2000), and; NGOs have access to the citizenry for support (Brown, 2012). The expectation for emergence of stakeholders fitting these categories influences management actions (Prell et al., 2009), for example through the structuring of stakeholder protocols, policy, planning, and analysis of the potential impacts of change. This creates the functional space specifically for these stakeholders in ENRM leading to repeated re-emergence of the 'usual suspects' (Reed et al., 2009).

In influential work on stakeholder analysis, again from business management, Mitchell et al. (1997) proposed a stakeholder analysis framework based on stakeholders' power, legitimacy, and urgency. Power describes the ability of a group to shape an issue to their own means, and can be in the form of financial resources, control over decision-making, or access to decision-makers and the media (Mitchell et al., 1997; Laplume et al., 2008; Crane and Ruebottom, 2011). Legitimacy is a subjective assessment of how genuine is a stakeholder's interest (for example, legitimacy would differentiate between claims based on impacts on one's livelihood versus instrumental use of the issue for political manoeuvring). Urgency is similar to legitimacy, but differs in that it incorporates consideration of the timescale of potential impact, delineating between stakeholders with a short-term interest compared to a long-term interest. Rowley and Moldoveanu (2003) explain that urgency can be antecedent to stakeholder mobilisation, suggesting that engagement with stakeholders viewed as having a sense of urgency may occur in order to avoid escalation of stakeholder opposition to the actions of a firm. In the translation of the stakeholder framework from a business management context for use in ENRM, urgency has been grouped with legitimacy, allowing a simplification of stakeholder analysis based on relative power and legitimacy. This perspective was presented by Reed et al. (2009), who use an interest-influence (i.e. legitimacy-power) grid to organise stakeholders in ENRM.

In the ENRM context, assessment of stakeholders' interest in an issue is built on the concept of legitimacy (Reed et al., 2009, p. 1941). As such, the term 'interest' is not deployed in a descriptive sense (i.e. describing the nature of a stakeholder's interest) but instead is used as a measure of the intensity or extent of interest (i.e. how much of an interest does a stakeholder hold?). In many theoretical and practical applications, stakeholders have been categorised along a continuum of low interest to high interest, with this implicitly indicating a measure of legitimacy. Influence, similarly, is based on the concept of power, and mapped on a continuum of low power to high power. Much like Freeman's (1984, p. 46) original definition, the concepts of power (or influence) and legitimacy (or interest) can be distilled into a structure of understanding stakeholders in terms of their ability to affect, or be affected by, a decision. Where identification of stakeholders in ENRM has a tendency to yield the usual suspects (Reed et al., 2009), the relative power and legitimacy dynamics will remain broadly consistent across issues: a private company with a high financial stake in land or a resource will always be considered a high power stakeholder, while a local community will always be considered high legitimacy, but often low-power. Legitimacy can, of course, be contested and the practical outcome in terms of the inclusion or role of any one group will depend on who has authority or jurisdictional control over the engagement process.

As a specific example that draws out the significance of real-world power and legitimacy in ENRM, we can look to the case of the proposal of a large-scale wind energy development in King Island, Australia, where the pre-existing power imbalance between a local community and the state-owned corporate proponent shaped how local community members perceived their ability to influence decisionmaking, even when ostensibly participatory techniques were adopted for incorporating community preferences (Colvin et al., 2018). In this case, some concerned community members formed an incorporated opposition group in order to attempt to rebalance the pre-existing power asymmetry between the corporate proponent and local community. As a result, though, other community members (especially those who were supportive of, or open to, the proposal) perceived the formation of the opposition group as creating a new power imbalance; one between the incorporated opposition group and 'everyone else' in the community. By the opposition group incorporating to amplify their dissenting voices in comparison to the corporate proponent, others in the community felt that their voices and power were, comparatively, diminished (Colvin et al., 2016b).

The social context - including access to and use of power and the legacy of prior inter-stakeholder relationships across other issues fundamentally shapes how stakeholders will interact with any given ENRM issue. This is the case in ENRM (Colvin et al., 2015; Lucas and Warman, 2018), and has been highlighted as a critical factor shaping firm-stakeholder relations in the business management context (Barnett, 2007). Accordingly, stakeholder theory in the ENRM context requires close attentiveness to what are the pre-existing social relationships that can affect inter-stakeholder relationships with an ENRM setting as the 'usual suspects' are likely to have interacted on previous issues and hold predispositions towards both other stakeholders and decision-makers.

\section{The centrality and depth of stakeholders' landscape perspectives in ENRM}

Due to the nature of ENRM issues, the orientation of stakeholders' interests often reflect their landscape preferences relevant within the geographical boundaries of the ENRM issue in question (de Chazal et al., 2008). It is therefore critical to engage with how stakeholders perceive of and value the landscape that is related to distinct ENRM issues in order to understand the nature of each's 'stake'. Here, we use the term 'landscape' broadly to describe terrestrial, coastal, and marine areas (and any combination of all three), with any degree of human-modification. Landscape perspectives can vary widely between individuals, and may be strongly held beliefs and deep-seated values reflecting the material and/or symbolic meaning of the landscape (Meinig, 1979; Greider and Garkovich, 1994; Saltzman et al., 2011; Brown, 2012). Landscape perspectives can also be interwoven with stakeholders' sense of who they are, such that a threat to a landscape can be experienced as a threat to the self (Manzo and Devine-Wright, 2014). As such, being a stakeholder may be a deeply personal experience for stakeholders engaged in ENRM; the stakes held by stakeholders can be of direct importance to their place in the world, such as their sense of self (Colvin et al., 2015), or livelihoods (Althor et al., 2018), or a combination of the two (Groth et al., 2014).

However, in the analytical stage of ENRM stakeholder analysis and engagement, it is commonplace to see ENRM scholars and practitioners seeking to predict and categorise stakeholders' landscape perspectives. Critically, ENRM stakeholders' preferences may be open to multiple interpretations by an external decision-maker who is categorising stakeholders from afar. For example, a resident of a regional town that is facing development of new renewable energy facilities may be grouped by decision-makers with all other local residents as this accords with the traditional stakeholder model. However, in reality the 'local residents' group will be highly heterogeneous, not because from the decisionmakers' perspective their relationship to the proposed energy facility differs but instead because the hypothetical resident may hold drastically different landscape perspectives compared to their neighbour. Such a situation may lead stakeholders, classified by external actors into 
the same group, to hold thoroughly oppositional stances on the ENRM issue. The question of how to best divide and categorise stakeholders, then, is wrapped up not only in the relationship between a person and the ENRM issue, but also - significantly - in their underlying landscape perspectives.

These underlying landscape perspectives can be deeply important to people (Stern and Dietz, 1994). A stakeholder's landscape perspectives can reflect one's fundamental values about how to best advance humanity toward some idealised state, whether that is through conserving nature and reducing human-caused impacts, or through developing nature in order to foster and realise human ingenuity (Price et al., 2014). Such positions are entirely subjective; there is no 'correct' value orientation and accordingly there can be no 'correct' landscape perspective. Despite this, one's landscape perspective can go beyond desiring or opposing a specific ENRM issue (such as the development of a mine or renewable energy facility, gazettal of a national park, changes to land tenure, expansion of private control of land management, construction of a transport corridor, residential rezoning or any other land use change or policy change among the multiplicity of ways in which people designate the landscape to one purpose over another) and instead be grounded in how the person interprets that landscape change to align with or oppose their values. What is important here to note is that in a single ENRM issue, there can be as many different landscape perspectives at play as there are stakeholders.

Here is a critical departure of ENRM from the origins of stakeholder theory in business management (Freeman, 1984), where stakeholders tend to be defined based on their formal relationship to a firm, by the firm. In the traditions of stakeholder theory, stakeholders are likely to be categorised into comparatively more sterile, clear-cut, and detached groups such as employees, suppliers, or customers (Billgren and Holmén, 2008; Reed, 2008). (Though we note here more contemporary critiques of stakeholder theory in the business context, too, that challenge the abstraction of business stakeholders from their lived social reality (McVea and Freeman, 2005; Miles, 2012)). By contrast, being an ENRM stakeholder will likely be a deeply personal experience for many people involved. Further, people engage with ENRM issues via a range of social structures, including as individuals, in formal organisations and groups as well as informal or implicit associations (Colvin et al., 2016a). For some of these types of social structures, the objective for organising into a group will be explicitly to advance a preferred landscape perspective and/or the underlying values that it expresses (Kahane et al., 2013). For others, it may be that an individual is employed by an organisation that is viewed as a stakeholder, opening further potential complications in how ENRM stakeholders are understood, as the organisation's landscape perspective may differ from those of an individual employee who is actively representing the organisation's interest in the issue.

In summary, being a stakeholder in ENRM has the potential to be a deeply personal experience, and one that is open to contestation based on who is doing the classifying, and how well that classification reflects, or even acknowledges, the stakeholder's landscape perspective. Accordingly, ENRM stakeholder processes cannot be viewed as an explicit and forthright process of taking a firm-centric approach and applying it to the ENRM setting. One's preferences for the landscape may be perceived entirely falsely by an external decision-maker who is operating on simplistic and traditional approaches to grouping stakeholders. Further, the landscape perspective one holds can be the expression of much deeper-seated values that extend into a person's sense of self and identity.

\section{Centring landscape perspectives in ENRM stakeholder analysis and engagement}

Translation of stakeholder theory from business management to ENRM similarly replaced the firm with the ENRM issue in question, often a landscape with a proposed land use change or a new policy with implications for the state of the landscape, as the centre of the network of stakeholders. As stakeholder theory conceptualised the relationships between stakeholders and the firm as a hub with spokes (Freeman, 1984), the identified stakeholders were defined based on their relationship to the firm, by the firm (Fig. 2a). This firm-centric perspective to the classification of stakeholders is matched by the positioning of decision-making power, in that power rests with the decision-makers within the firm 'looking outward' toward the stakeholders (Crane and Ruebottom, 2011; Miles, 2015). Though it may not always produce analyses favoured by all stakeholders, in the firm-centric approach the firm is the self-defining 'hub' that participates in and articulates the relationships between each stakeholder and the firm. The firm then holds the decision-making power to act on the relationships with each stakeholder and shape the nature of future firm-stakeholder engagements (Barnett, 2007).

In ENRM, the landscape in which the ENRM issue is embedded becomes the 'hub', and decision-making power sits with any one or several of the stakeholders on the spokes, depending on the nature of the ENRM issue (Billgren and Holmén, 2008). This contrasts subtly but significantly with the application of stakeholder theory in the business context, as the decision-makers in ENRM sit on the spokes of the relationship 'looking inward' toward the ENRM issue, the landscape in which it is embedded, and across to the other stakeholders (Fig. 2b). As a result, while the decisions about a firm are made by the firm and are informed by the perspective of the firm, in ENRM, decisions about a landscape are made by one of several stakeholders, and cannot be informed by the perspectives of the landscape; rather the decision is informed by the perspectives of whichever stakeholder carries the decision-making power. This is both with regard to defining the ENRM issue and its landscape (the 'hub') based on their landscape perspectives, and categorising stakeholders (the other 'spokes') based on assumptions about their relationship to the ENRM issue and landscape.

A clear point of disjuncture in ENRM is between those stakeholders who reside within the landscape in question, and those stakeholders that are external to it (Fig. 3). To illustrate the complexity of ENRM stakeholders and their proximity to the landscape, we can consider the tangled views on power and legitimacy represented by an ENRM dispute in Australia in mid-2019. The ENRM dispute concerned a proposed thermal coal mine, which became the focal point for Australian environmental and climate campaigns. In a bounded protest action, a 'convoy' of mine opponents drove from southern Australia northwards to converge at the regional town nearest the proposed mine site. This protest action received a high amount of media coverage, with a strong focus on the conflict between local and extra-local stakeholders, and was implicated in the result of the subsequent Australian federal election due to its interaction with the legacy of Australian ENRM politics more generally (Colvin, 2020). This example captures the complexity of the mine as an ENRM issue that can be viewed in a range of ways so as to privilege the landscape perspectives of certain stakeholders above others, depending on whether the issue is perceived to be a local, bounded issue requiring local decision-making or one of national interest requiring extra-local stakeholder input (e.g. Juerges and Newig, 2015).

As the symbolic meaning of the landscape can differ significantly between individuals and organisations, and stakeholders' interests reflect their landscape perspectives (which are in turn informed by their values) (Meinig, 1979; Greider and Garkovich, 1994; Saltzman et al., 2011; Brown, 2012), the way the landscape is perceived by decision-makers is also very likely to differ from other stakeholders' perspectives.

In addition to the unequal distribution of power across stakeholders in ENRM, decision-makers' landscape perspectives are by default privileged above the likely different landscape perspectives of other stakeholders. So while both stakeholder theory in business management and stakeholder analysis and engagement in ENRM share the commonality of being focused on stakeholder management, there are critical 


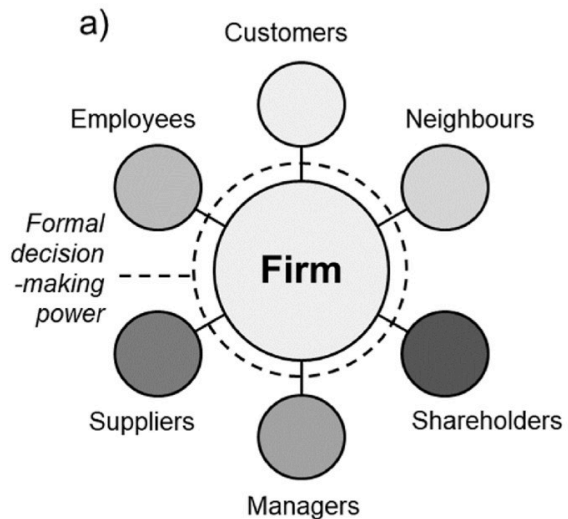

b)

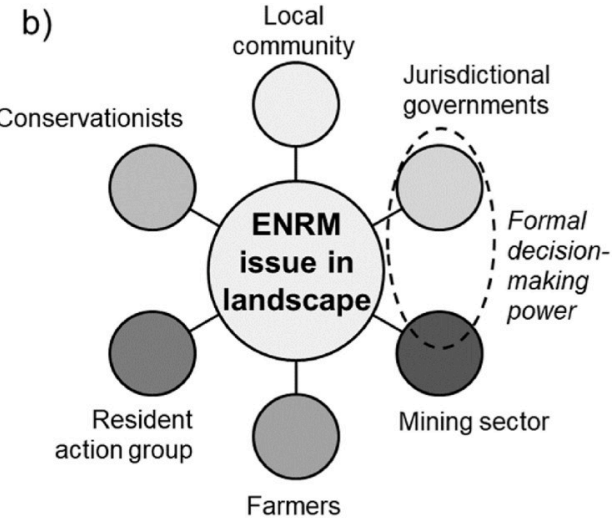

Fig. 2. The hub and spoke model of the firm and its stakeholders (Freeman, 1984). Diagram a) shows a simplified conceptualisation of the relationship between firm and stakeholders, from business management origins. Diagram b) shows how this understanding applies in an ENRM example such as mining development, where the firm as the hub is replaced by the landscape and relevant/typical stakeholder categories are identified, drawing out positions within or outside of the landscape in question. The locus of decision-making power is shown by dashed lines.

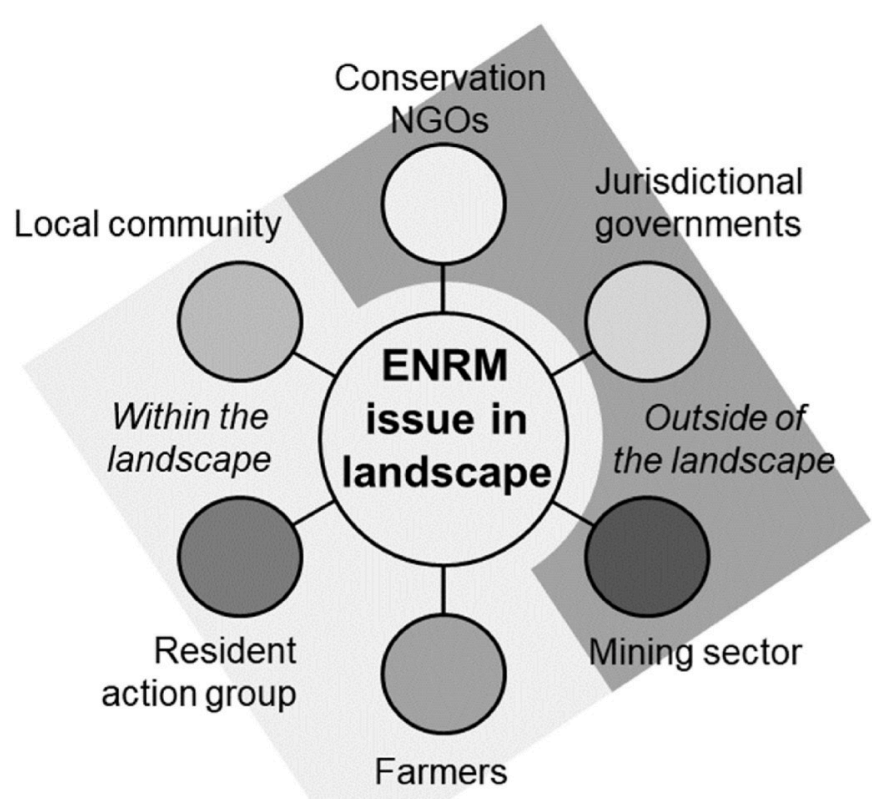

Fig. 3. A representation of how ENRM stakeholders may reside within or outside of the landscape.

differences between the two contexts. These differences between contexts (Table 2) highlight the complexity of adapting stakeholder theory from its origins in business management to solve challenges in ENRM.

\section{Ways forward: foregrounding power, perspective, and privilege in ENRM}

In this essay we interrogated of the consequences of translating stakeholder theory from the business management context to ENRM. We emphasised that there are contextual differences between the business and ENRM contexts that go beyond changing labels on a hub and spoke diagram. This leads to disputes over how the landscape is, and ought to be, defined, and the legitimacy of various stakeholders' claims over contested ENRM issues and the landscapes in which they are embedded. Based on this essay, we now present ways forward.

For ENRM scholars and practitioners, being cognisant of these privileges of power and perspective will contribute to good practice in stakeholder analysis and engagement. Here, we offer some practical perspectives drawn from the ENRM and sustainability literature that can support the enactment of such good practices. A reflexive and explicit perspective on power in ENRM is necessary (e.g. Moon et al., 2019). ENRM is well placed to do this, and especially so in the context of stakeholder analysis and engagement as consideration of power is already embedded in good practice. However, this must be extended to recognise that ENRM decision-making processes are not isolated from broader social dynamics. The pre-existing power dynamics - such as class, status, social and other capital held by groups, capacity and access to decision-makers and resources - should be explicitly acknowledged. Similarly, it must be acknowledged that some actors that hold decision-making power are in the dual role of adjudicator and privileged stakeholder, such as government agencies. In such cases they are non-neutral entities driving ENRM decision processes. All stakeholders will hold their own socially constructed understanding of the landscape informed by their values, and it is essential to disentangle these differing landscape perspectives from any assertion of 'right' or 'wrong'. Additionally, our discussion of the landscape as a non-sentient entity is grounded within western conceptualisations of the relationship between humans and nature. This is not the case in other cultural contexts, including the cultures of some Indigenous peoples and First Nations in western settler-colonial nations where the question of power is only more critical (Banerjee, 2000).

Facilitating a shared understanding between stakeholders of where perspectives on the landscape align and differ will help to make explicit those often hidden assumptions about the meaning of the landscape, the values that underpin them, and work toward recognising the legitimacies of different stakeholders. This is particularly important in cases where the landscape preferences and values of those with decisionmaking power align with the preferences and values of some, but not all, stakeholders (e.g. Witt, 2013). In cases where decision-making power defines the landscape in a specific way based on selective values, it will be important to bring about recognition of the validity of

Table 2

Key points of difference between stakeholder theory in the business management and ENRM contexts.

\begin{tabular}{|c|c|}
\hline Origins in business management & Application in environmental and natural resources management (ENRM) \\
\hline Firm (hub) is subject that defines stakeholder identification. & Landscape (hub) is object that defines stakeholder identification. \\
\hline Firm (hub) is the object that defines itself. & Landscape (hub) is object that is defined by each stakeholder (spokes). \\
\hline $\begin{array}{l}\text { Power for decision-making and determining stakeholders' legitimacies is } \\
\text { centred on the firm (hub), looking out at the stakeholders (spokes). }\end{array}$ & $\begin{array}{l}\text { Power for decision-making power and determining stakeholders' legitimacies is decentred on a } \\
\text { privileged stakeholder (spoke), looking at the landscape (hub) and other stakeholders (spokes). }\end{array}$ \\
\hline $\begin{array}{l}\text { Stakeholder classifications are based on measurable and mutually understood } \\
\text { relationships, centred on the firm. }\end{array}$ & $\begin{array}{l}\text { Stakeholder classifications are more emotive and based on values, with some stakeholders residing } \\
\text { within the landscape and others outside of it. }\end{array}$ \\
\hline
\end{tabular}


differing landscape preferences and the values that underpin them.

The translation of the hub-and-spoke stakeholder model from business management to the ENRM context has offered extraordinarily useful means for enabling broader participation in environmental decision-making (Reed, 2008). In this paper we have argued that there are additional complexities in the ENRM context that necessitate further examination of the relationship between landscape perspectives and decision-making power. Together, these three dimensions can interact in the business management-informed ENRM stakeholder context to privilege certain landscape perspectives over others.

We encourage in ENRM scholarship and practice an explicitly landscape-centric approach to stakeholder analysis and engagement. We can explore why through an illustrative example of a resources company seeking to develop a greenfield mine. While a traditional business management approach to stakeholder analysis in such a case may consider the mining company as the firm at the centre of the hub, this would inherently limit the ability for stakeholder analysis and engagement to navigate through the complexity of stakeholders' various and competing landscape perspectives, and therefore the true nature of their priorities or grievances. In the ENRM context, when the subject of a decision concerns a landscape, directly or indirectly, centring the landscape in the hub-and-spoke model is a reminder of the multiplicity of landscape perspectives that must be considered and negotiated in the decision process.

In addition to a landscape-centric approach, we also encourage overlay of a power lens on ENRM stakeholder analysis and engagement. We have argued that some landscape perspectives will inherently become privileged, by being held by high-power stakeholders, particularly including those with direct access to decision-making power. In response to these risks of privileging certain perspectives over others, in ENRM, scholars and practitioners may commit time to building shared understandings between stakeholders with different landscape perspectives. Explicitly unpacking the stakeholders' landscape perspectives and their underlying values (and consequently stakeholders' preferences for management priorities, e.g. development, protection, recreation) will assist stakeholders and decision-makers to understand root causes of disagreements (Colloff et al., 2018). This will also assist ENRM scholars and practitioners to appreciate the complexity of stakeholders' perspectives on the landscape (Anderson et al., 2013).

Shared understandings of landscape perspectives and experiences of power can be developed through facilitated processes of meaningful dialogue, where stakeholders "are able to gain a mutual respect for and an understanding of each other's viewpoints" (Boully et al., 2005, p.1). Dialogue-based processes are familiar in the ENRM context, and emphasise deliberation, listening, collaboration, and relationship building. These processes are most successful when facilitated by intermediaries trained in spanning boundaries of different knowledge systems and institutional structures who can manage competing interests and mediate power differences (Moore, 2013; Cvitanovic et al., 2015; Bednarek et al., 2018). Ultimately, such processes should seek to build functional trust between stakeholders (Hamm, 2017; Lacey et al., 2018) and be directed toward elucidating a shared understanding of the diversity of perspectives that can contribute to fair ENRM outcomes (Gross, 2007; Lacey et al., 2017). Adopting dialogue processes that centre the exploration of landscape perspectives would allow for the reflexive decision-maker to note when there is a risk of privileging some landscape perspectives, including their own, over others.

\section{Concluding remarks}

These perspectives on the translation of stakeholder theory from business management to ENRM demonstrate that while stakeholder analysis and engagement scholarship and practice aim to facilitate public participation in ENRM decision-making, there are some limitations. The hub-and-spoke model infers a certainty of stakeholders' landscape perspectives and underlying values that cannot be realised in the ENRM context. This risks the privileging of the landscape perspectives held by those with decision-making power, and the subordination of those that differ.

We encourage cognisance of the privileges of power and perspective in ENRM for scholars and practitioners, and more specifically recommend adopting practices that foreground subjectivities of perspective, and make explicit and legitimate the varying landscape preferences that are held by stakeholders. Recognition that decision-makers do not hold a mortgage over a 'correct' or superior landscape preference is important. The plurality of landscape perspectives and consequently on ENRM should be accepted as a fundamental and immutable aspect of ENRM scholarship and practice, and their sharing between stakeholders enabled. Ultimately, ENRM scholars and practitioners have a professional privilege that allows the space to consider and recognise the consequences of the theories and practices that are central to ENRM, such as stakeholder theory and stakeholder analysis and engagement practices. By so doing, ENRM scholars and practitioners can work towards stakeholder processes that recognise the legitimacy of a range of landscape preferences and values in ENRM decision-making, and do not inadvertently perpetuate power imbalances through the privilege of aligning their decision-making power with their landscape perspectives.

\section{Declaration of competing interest}

The authors declare that they have no known competing financial interests or personal relationships that could have appeared to influence the work reported in this paper.

\section{CRediT authorship contribution statement}

R.M. Colvin: Conceptualization, Investigation, Writing - original draft, Writing - review \& editing. G. Bradd Witt: Writing - original draft, Writing - review \& editing. Justine Lacey: Writing - original draft, Writing - review \& editing.

\section{Acknowledgements}

This first conceptualisation of this work was in RMC's PhD thesis. It was therefore enabled by RMC's PhD Scholarships: The University of Queensland and Commonwealth Scientific and Industry Research Organisation 'Integrated Natural Resource Management' top-up scholarship, and the Australian Government 'Australian Postgraduate Award'.

\section{References}

Aanesen, M., Armstrong, C.W., Bloomfield, H.J., Röckmann, C., 2014. What does stakeholder involvement mean for fisheries management? Ecol. Soc. 19 [Online]. Althor, G., Mahood, S., Witt, B., Colvin, R.M., Watson, J.E.M., 2018. Large-scale environmental degradation results in inequitable impacts to already impoverished communities: a case study from the floating villages of Cambodia. Ambio 47, 747 459.

Anderson, N.M., Williams, K.J.H., Ford, R.M., 2013. Community perceptions of plantation forestry: the association between place meanings and social representations of a contentious rural land use. J. Environ. Psychol. 34, 121-136. Arnstein, S.R., 1969. A ladder of citizen participation. J. Am. Inst. Plan. 35, 216-224. Banerjee, S.B., 2000. Whose land is it anyway? National interest, indigenous stakeholders, and colonial discourses:the case of the jabiluka uranium mine. Organization \& Environment 13, 3-38.

Barnett, M.L., 2007. Stakeholder influence capacity and the variability of financial returns to corporate social responsibility. Acad. Manag. Rev. 32, 794-816.

Bednarek, A.T., Wyborn, C., Cvitanovic, C., Meyer, R., Colvin, R.M., Addison, P.F.E., Close, S.L., Curran, K., Farooque, M., Goldman, E., Hart, D., Mannix, H., McGreavy, B., Parris, A., Posner, S., Robinson, C., Ryan, M., Leith, P., 2018. Boundary spanning at the science-policy interface: the practitioners' perspectives. Sustainability Science 13, 1175-1183.

Beedell, J., Rehman, T., 2000. Using social-psychology models to understand farmers' conservation behaviour. J. Rural Stud. 16, 117-127.

Billgren, C., Holmén, H., 2008. Approaching reality: comparing stakeholder analysis and cultural theory in the context of natural resource management. Land Use Pol. 25, $550-562$. 
Boully, L., McCollum, B., Vanderbyl, T., Claydon, G., 2005. Talking until the talking starts: resolving conflict through dialogue. In: The International Conference on Engaging Communities, 14-17 August (Brisbane, Australia).

Brown, G., 2012. Public participation GIS (PPGIS) for regional and environmental planning: reflections on a decade of empirical research. URISA J. 25, 7-18.

Brummans, B., Putnam, L., Gray, B., Hanke, R., Lewicki, R., Weithoff, C., 2008. Making sense of intractable multiparty conflict: a study of framing in four environmental disputes. Commun. Monogr. 75, 25-51.

Bryan, T.A., 2008. Aligning identity: Social identity and Changing Context in CommunityBased Environmental Conflict. PhD. The University of Michigan.

Bryson, J.M., 2004. What to do when stakeholders matter. Publ. Manag. Rev. 6, 21-53.

Buijs, A.E., Lawrence, A., 2013. Emotional conflicts in rational forestry: towards a research agenda for understanding emotions in environmental conflicts. For. Pol. Econ. 33, 104-111.

Carr, S., Tait, J., 1991. Differences in the attitudes of farmers and conservationists and their implications. J. Environ. Manag. 32, 281-294.

Carson, L., 2009. Deliberative public participation and hexachlorobenzene stockpiles. J. Environ. Manag. 90, 1636-1643.

Clarkson, M.B.E., 1995. A stakeholder framework for analyzing and evaluating corporate social performance. Acad. Manag. Rev. 20, 92-117.

Colloff, M.J., Doody, T.M., Overton, I.C., Dalton, J., Welling, R., 2018. Re-framing the decision context over trade-offs among ecosystem services and wellbeing in a major river basin where water resources are highly contested. Sustain. Sci. 14, 713-731.

Colvin, R.M., 2020. Social identity in the energy transition: an analysis of the "Stop Adani Convoy" to explore social-political conflict in Australia. Energy Research \& Social Science 66, 101492.

Colvin, R.M., Witt, G.B., Lacey, J., 2015. The social identity approach to understanding socio-political conflict in environmental and natural resources management. Global Environ. Change 34, 237-246.

Colvin, R.M., Witt, G.B., Lacey, J., 2016a. Approaches to identifying stakeholders in environmental management: insights from practitioners to go beyond the 'usual suspects'. Land Use Pol. 52, 266-276.

Colvin, R.M., Witt, G.B., Lacey, J., 2016b. How wind became a four-letter word: lessons for community engagement from a wind energy conflict in King Island, Australia. Energy Pol. 98, 483-494.

Colvin, R.M., Witt, G.B., Lacey, J., 2018. Using a community vote for wind energy development decision-making in king Island, tasmania. Case Studies in the Environment.

Colvin, R.M., Witt, G.B., Lacey, J., Witt, K., 2019. The community cost of consultation: characterising the qualitative social impacts of a wind energy development that failed to proceed in Tasmania, Australia. Environ. Impact Assess. Rev. 77, 40-48.

Crane, A., Ruebottom, T., 2011. Stakeholder theory and social identity: rethinking stakeholder identification. J. Bus. Ethics 102, 77-87.

Cundy, A.B., Bardos, R.P., Church, A., Puschenreiter, M., Friesl-Hanl, W., Müller, I., Neu, S., Mench, M., Witters, N., Vangronsveld, J., 2013. Developing principles of sustainability and stakeholder engagement for "gentle" remediation approaches: the European context. J. Environ. Manag. 129, 283-291.

Cvitanovic, C., Hobday, A.J., van Kerkhoff, L., Wilson, S.K., Dobbs, K., Marshall, N.A., 2015. Improving knowledge exchange among scientists and decision-makers to facilitate the adaptive governance of marine resources: a review of knowledge and research needs. Ocean Coast Manag. 112, 25-35.

de Chazal, J., Quétiera, F., Lavorela, S., Van Doornc, A., 2008. Including multiple differing stakeholder values into vulnerability assessments of socio-ecological systems. Global Environ. Change 18, 508-520.

Fischer, A.R.H., Wentholt, M.T.A., Rowe, G., Frewer, L.J., 2014. Expert involvement in policy development: a systematic review of current practice. Sci. Publ. Pol. 41, 332-343.

Fox, E., Poncelet, E., Connor, D., Vasques, J., Ugoretz, J., McCreary, S., Monie, D., Harty, M., Gleason, M., 2013. Adapting stakeholder processes to region-specific challenges in marine protected area network planning. Ocean Coast Manag. 74, 24-33.

Freeman, R.E., 1984. Strategic Management: A Stakeholder Approach. Pitman, Boston, MA.

Greider, T., Garkovich, L., 1994. Landscapes: the social construction of nature and the environment. Rural Sociol. 59, 1-24.

Grimble, R., Wellard, K., 1997. Stakeholder methodologies in natural resource management: a review of principles, contexts, experiences and opportunities. Agric. Syst. 55, 173-193.

Gross, C., 2007. Community perspectives of wind energy in Australia: the application of a justice and community fairness framework to increase social acceptance. Energy Pol. $35,2727-2736$.

Groth, T.M., Curtis, A., Mendham, E., Toman, E., 2014. Farmer identity in multifunctional landscapes: using a collective identity construct to explore the nature and impact of occupational identity. Aust. Geogr. 45, 71-86.

Guerrero, A.M., McAllister, R.R.J., Corcoran, J., Wilson, K.A., 2013. Scale mismatches, conservation planning, and the value of social-network analyses. Conserv. Biol. 27, 35-44.

Hamm, J.A., 2017. Trust, trustworthiness, and motivation in the natural resource management context. Soc. Nat. Resour. 30, 919-933.

Hindmarsh, R., Matthews, C., 2008. Deliberative speak at the turbine face: community engagement, wind farms, and renewable energy transitions, in Australia. J. Environ. Pol. Plann. 10, 217-232.

IAP2, 2015. Quality assurance Standard for Community and stakeholder engagement. International association for public participation. Available: http://www.iap2.org. au/documents/item/391.
Juerges, N., Newig, J., 2015. What role for frames in scalar conflicts? Land Use Pol. 49, 426-434.

Kächele, H., Dabbert, S., 2002. An economic approach for a better understanding of conflicts between farmers and nature conservationists - an application of the decision support system MODAM to the Lower Odra Valley National Park. Agric. Syst. 74, 241-255.

Kahane, D., Lopston, K., Herriman, J., Hardy, M., 2013. Stakeholder and citizen roles in public deliberation. Journal of Public Deliberation 9.

Kash, J., 2008. Enemies to allies: the role of policy-design adaptation in facilitating a farmer-environmentalist alliance. Pol. Stud. J. 36, 39-60.

Kindermann, G., Gormally, M.J., 2013. Stakeholder perceptions of recreational and management impacts on protected coastal dune systems: a comparison of three European countries. Land Use Pol. 31, 472-485.

Kivits, R.A., 2011. Three component stakeholder analysis. Int. J. Mult. Res. Approaches 5, 318-333.

Lacey, J., Carr-Cornish, S., Zhang, A., Eglinton, K., Moffat, K., 2017. The art and science of community relations: procedural fairness at Newmont's Waihi Gold operations, New Zealand. Resour. Pol. 52, 245-254.

Lacey, J., Howden, M., Cvitanovic, C., Colvin, R.M., 2018. Understanding and managing trust at the climate science-policy interface. Nat. Clim. Change 8, 22-28.

Lacey, J., Lamont, J., 2014. Using social contract to inform social licence to operate: an application in the Australian coal seam gas industry. J. Clean. Prod. 84, 831-839.

Laplume, A.O., Sonpar, K., Litz, R.A., 2008. Stakeholder theory: reviewing a theory that moves us. J. Manag. 34, 1152-1189.

Lewicki, R.J., Gray, B., Elliott, M. (Eds.), 2003. Making Sense of Intractable Environmental Conflicts: Concepts and Cases. Island Press, Washington, D.C.

Lockwood, M., Davidson, J., Curtis, A., Stratford, E., Griffith, R., 2010. Governance principles for natural resource management. Soc. Nat. Resour. 23, 986-1001.

Lucas, C., Warman, R., 2018. Disrupting polarized discourses: can we get out of the ruts of environmental conflicts? Environment and Planning C: Politics and Space 36, 987-1005, 0, 2399654418772843.

Place attachment. In: Manzo, L.C., Devine-Wright, P. (Eds.), 2014. Advances in Theory, Methods and Applications. Routledge, London and New York.

McVea, J., Freeman, R., 2005. A names-and-faces approach to stakeholder management: how focusing on stakeholders as individuals can bring ethics and entrepreneurial strategy together. Journal of Management Enquiry 14, 57-69.

Measham, T., Fleming, D., 2013. Lessons from developments of resource extraction industries in rural areas: a literature review. CSIRO. Available: http://www.gisera.or g.au/publications/tech_reports_papers/socioeco-proj-1-lit-review.pdf.

Meinig, D.W., 1979. The beholding eye: ten versions of the same scene. In: MEINIG, D. W., BRINCKERHOFF JACKSON, J. (Eds.), The Interpretation of Ordinary Landscapes: Geographical Essays. Oxford University Press, New York.

Miles, S., 2012. Stakeholder: essentially contested or just confused? J. Bus. Ethics 108.

Miles, S., 2015. Stakeholder theory classification: a theoretical and empirical evaluation of definitions. J. Bus. Ethics 1-23.

Miller, A., 1999. Environmental Problem Solving: Psychosocial Barriers to Adaptive Change. Springer, New York.

Mitchell, R.K., Agle, B.R., Wood, D.J., 1997. Toward a theory of stakeholder identification and salience: defining the principle of who and what really counts. Acad. Manag. Rev. 22, 853-886.

Mohai, P., 1987. Public participation and natural resource decision-making: the case of the RARE II decisions. Nat. Resour. J. 27, 123-155.

Moon, K., Blackman, D.A., Adams, V.M., Colvin, R.M., Davila, F., Evans, M.C., Januchowski-Hartley, S.R., Bennett, N.J., Dickinson, H., Sandbrook, C., Sherren, K., St John, F.A.V., van Kerkhoff, L., Wyborn, C., 2019. Expanding the role of social science in conservation through an engagement with philosophy, methodology, and methods. Methods in Ecology and Evolution 10, 294-302.

Moore, E.A., Koontz, T.M., 2003. Research note A typology of collaborative watershed groups: citizen-based, agency-based, and mixed partnerships. Soc. Nat. Resour. 16, $451-460$.

Moore, L., 2013. Common Ground on Hostile Turf: Stories from an Environmental Mediator. Island Press, Washington, D.C.

North, D.W., Stern, P.C., Webler, T., Field, P., 2014. Public and stakeholder participation for managing and reducing the risks of shale gas development. Environ. Sci. Technol. 48, 8388-8396.

Parsons, R., Lacey, J., Moffat, K., 2014. Maintaining legitimacy of a contested practice: how the minerals industry understands its 'social licence to operate'. Resour. Pol. 41, 83-90.

Phillips, R.A., Reichart, J., 2000. The environment as a stakeholder? A fairness-based approach. J. Bus. Ethics 23, 185-197.

Prell, C., Hubacek, K., Reed, M., Quinn, C., Jin, N., Holden, J., Burt, T., Kirby, M., Sendzimir, J., 2007. If you have a hammer everything looks like a nail: traditional versus participatory model building. Interdiscipl. Sci. Rev. 32, 263-282.

Prell, C., Hubacek, K., Reed, M.S., 2009. Stakeholder analysis and social network analysis in natural resource management. Soc. Nat. Resour. 22, 501-518.

Price, J.C., Walker, I.A., Boschetti, F., 2014. Measuring cultural values and beliefs about environment to identify their role in climate change responses. J. Environ. Psychol. 37, 8-20.

Rastogi, A., Badola, R., Hussain, S.A., Hickey, G.M., 2010. Assessing the utility of stakeholder analysis to protected areas management: the case of Corbett National Park, India. Biol. Conserv. 143, 2956-2964.

Redpath, S.M., Young, J., Evely, A., Adams, W.M., Sutherland, W.J., Whitehouse, A., Amar, A., Lambert, R.A., Linnell, J.D.C., Watt, A., Gutierrez, R.J., 2013. Understanding and managing conservation conflicts. Trends Ecol. Evol. 28, 100-109. 
Reed, M., 2008. Stakeholder participation for environmental management: a literature review. Biol. Conserv. 141, 2417-2431.

Reed, M., Graves, A., Dandy, N., Posthumus, H., Hubacek, K., Morris, J., Prell, C., Quinn, C., Stringer, L., 2009. Who's in and why? A typology of stakeholder analysis methods for natural resource management. J. Environ. Manag. 90, 1933-1949.

Reed, M.S., Kenter, J., Bonn, A., Broad, K., Burt, T.P., Fazey, I.R., Fraser, E.D.G., Hubacek, K., Nainggolan, D., Quinn, C.H., Stringer, L.C., Ravera, F., 2013. Participatory scenario development for environmental management: a methodological framework illustrated with experience from the UK uplands. J. Environ. Manag. 128, 345-362.

Ross, H., Baldwin, C., Carter, R.W., 2016. Subtle implications: public participation versus community engagement in environmental decision-making. Australas. J. Environ. Manag. 23, 123-129.

Rowe, G., Frewer, L.J., 2000. Public participation methods: a framework for evaluation. Sci. Technol. Hum. Val. 25, 3-29.

Rowley, T.J., Moldoveanu, M., 2003. When will stakeholder groups act? An interest- and identity-based model of stakeholder group mobilization. Acad. Manag. J. 28, 204-219.

Saltzman, K., Head, L., Stenseke, M., 2011. Do cows belong in nature? The cultural basis of agriculture in Sweden and Australia. J. Rural Stud. 27, 54-62.

Sample, V., 1993. A framework for public participation in natural resource decision making, 91, 22-27.

Silverstri, S., Zaibet, L., Said, M.Y., Kifugo, S.C., 2013. Valuing ecosystem services for conservation and development purposes: a case study from Kenya. Environ. Sci. Pol. 31, 23-33.

Soma, K., Vatn, A., 2014. Representing the common goods - stakeholders vs. citizens. Land Use Pol. 41, 325-333.

Starik, M., 1995. Should trees have managerial standing? Toward stakeholder status for non-human nature. J. Bus. Ethics 14, 207-217.

Stern, P., Dietz, T., 1994. The value basis of environmental concern. J. Soc. Issues 50, 65-84.
Treffny, R., Beilin, R., 2011. Gaining legitimacy and losing trust: stakeholder participation in ecological risk assessment for marine protected area management. Environ. Val. 20, 417-438.

Ulibarri, N., Scott, T.A., Perez-Figueroa, O., 2019. How does stakeholder involvement affect environmental impact assessment? Environ. Impact Assess. Rev. 79, 106309.

Uribe, D., Geneletti, D., del Castillo, R.F., Orsi, F., 2014. Integrating stakeholder preferences and GIS-based multicriteria analysis to identify forest landscape restoration priorities. Sustainability 6, 935-951.

Van Assche, K., Beunen, R., Duineveld, M., Gruezmacher, M., 2017. Power/knowledge and natural resource management: foucaultian foundations in the analysis of adaptive governance. J. Environ. Pol. Plann. 19, 308-322.

Walker, P., 2006. How the West was one: American environmentalists, farmers and ranchers learn to say 'Howdy, partner. Outlook Agric. 35, 129-135.

Weber, M., 1978. Economy and Society: an Outline of Interpretive Sociology. Univ of California Press.

Wilson, G.A., 2004. The Australian Landcare movement: towards 'post-productivist' rural governance? J. Rural Stud. 20, 461-484.

Winter, C., Lockwood, M., 2004. The natural area value scale: a new instrument for measuring natural area values. Australas. J. Environ. Manag. 11, 11-20.

Witt, G.B., 2013. Vegetation changes through the eyes of the locals: the 'artificial wilderness' in the mulga country of south-west Queensland. Rangel. J. 35, 299-314.

Witt, G.B., Witt, K.J., Carter, R.W., Gordon, A., 2009. Exploring the 'city-bush divide' what do urban people really think of farmers and rural land management? Australas. J. Environ. Manag. 16, 168-180.

Yasmi, Y., Schanz, H., Salim, A., 2006. Manifestation of conflict escalation in natural resource management. Environ. Sci. Pol. 9, 538-546.

Zammit, C., Cockfield, G., Funnell, S., 2000. An Outcomes-Based Framework for Evaluating Natural Resources Management Policies and Programs. Project Report (Project No. USQ3), Social and Institutional Research Program, Land and Water Australia. 